LA INVENCIÓN DEL PATRIMONIO NATURAL EN ESPAÑA. POLÍTICA, ACADEMIA, ACTIVISMO Y COMUNICACIÓN /

THE INVENTION OF NATURAL HERITAGE IN SPAIN. POLITICS, ACADEMY, ACTIVISM AND COMMUNICATION

\section{EL ESPECTÁCULO DE LA CONSERVACIÓN. EL PARQUE NACIONAL DE DOÑANA EN EL HOMBRE Y LA TIERRA (1979)}

\author{
Mònica Alcalá-Lorente \\ Universitat Autònoma de Barcelona \\ moallor86@gmail.com \\ Carlos Tabernero \\ Universitat Autònoma de Barcelona \\ carlos.tabernero@uab.cat
}

\section{THE SPECTACLE OF CONSERVATION. DOÑANA NATIONAL PARK IN MAN AND THE EARTH (1979)}

Cómo citar este artículo/Citation: Alcalá-Lorente, M. y Tabernero, C. (2016). El espectáculo de la conservación. El Parque Nacional de Doñana en El Hombre y la Tierra (1979). Arbor, 192 (781): a347. doi: http://dx.doi.org/10.3989/ arbor.2016.781n5005

Recibido: 25 febrero 2015. Aceptado: 09 octubre 2015.

RESUMEN: A finales de la década de los setenta, se emitieron cuatro documentales dedicados al Parque Nacional de Doñana en la serie de Televisión Española El Hombre y la Tierra, dirigida por Félix Rodríguez de la Fuente. A través del relato del ciclo vital en el Parque -cada documental se correspondía con una estación del año-, estos capítulos constituyeron una celebración de la lucha por la conservación del patrimonio natural, cuyo significado se articuló en relación con una cuidada representación tanto de la naturaleza como de las ciencias naturales. Este artículo analiza cómo en un contexto histórico y político muy complejo, y mediante el espectáculo del éxito y de la fragilidad del Parque Nacional de Doñana, Rodríguez de la Fuente representó la sensibilidad hacia la naturaleza, hacia el patrimonio natural, adquirida con el estudio de las ciencias naturales, como una pieza clave de modernización.

PALABRAS CLAVE: televisión; patrimonio natural; ciencias naturales; conservación; Parque Nacional de Doñana; El Hombre y la Tierra; Félix Rodríguez de la Fuente.
Copyright: ( $) 2016$ CSIC. Este es un artículo de acceso abierto distribuido bajo los términos de la licencia Creative Commons Attribution (CC BY) España 3.0.
ABSTRACT: By the end of the 1970s, four documentaries about Doñana National Park were broadcast within the National Spanish Television series Man and the Earth, directed by Félix Rodríguez de la Fuente. Through the account of the Park's life cycle -each chapter matched each one of the year's seasons-, these chapters were a celebration of the struggle to conserve the natural heritage, whose meaning was established in relation to a beautifully-produced representation of both nature and the natural sciences. This paper analyzes how, in a quite complex historical and political context, and through the spectacle of the success and fragility of Doñana National Park, Rodríguez de la Fuente represented sensitivity towards nature and the natural heritage, acquired through the study of the natural sciences, as a key element of modernization.

KEYWORDS: television; natural heritage; natural sciences; conservation; Doñana National Park; Man and the Earth; Félix Rodríguez de la Fuente. 


\section{INTRODUCCIÓN}

En el mes de marzo de 1979, Televisión Española emitió los cuatro capítulos que Félix Rodríguez de la Fuente (1928-1980) dedicó al Parque Nacional de Doñana en la "Serie Ibérica" de El Hombre y la Tierra (1974-1981)1. A esas alturas, y después de cinco años en antena, el programa gozaba de reconocido prestigio dentro y fuera de las fronteras españolas, así como de amplia aceptación por parte de los espectadores. Aparte de los premios y reconocimientos recibidos tanto en España como en diversos festivales internacionales de televisión, El Hombre y la Tierra se había mantenido sin problema entre los programas mejor valorados de la parrilla televisiva desde el comienzo de su emisión en 1974 (Salcedo de Prado, 2008; Varillas, 2010) (figura 1). Cuando comenzó a emitirse, en la década de los 70 , la televisión ya se había consolidado como el principal medio de información y entretenimiento, con una amplia presencia en los hogares españoles (Palacio, 2001; Rueda Laffond, 2005; Díaz, 2006; Rueda Laffond y Coronado Ruiz, 2010). Sin embargo, la oferta televisiva se reducía a tan solo dos canales públicos, con lo cual es fácil suponer que una gran mayoría, si no la práctica totalidad de la población veía la serie, más teniendo en cuenta su excelente y bien conocida ubicación estratégica en la parrilla de programación. Tras algunos cambios durante la emisión de la "Serie Venezolana" en 1974, El Hombre y la Tierra ocupó, a partir del comienzo de la emisión de la "Serie Ibérica" en marzo de 1975 y hasta 1980, uno de los espacios más codiciados del prime time en la primera cadena, que acaparaba la mayor parte de la audiencia: los viernes por la noche, entre las 21:30 y las 22:30, justo entre la Segunda Edición del Telediario, el programa informativo de referencia del momento, y durante buena parte de su andadura, dependiendo de temporadas de producción y emisión, el programa Un, dos, tres... responda otra vez, concurso creado y dirigido por Narciso Ibáñez Serrador, e igualmente uno de los programas más exitosos, longevos y exportados de la televisión pública en España (Moreno Díaz, 2014) (figura 1)².

En 1979, el principal protagonista de estos cuatro capítulos de El Hombre y la Tierra, el Parque Nacional de Doñana, llevaba ya tiempo consolidado como piedra angular de la conservación y de la política medioambiental en España. La opinión pública conocía bien su notoriedad internacional, propiciada por las circunstancias de sus orígenes, su relación con el World Wildlife Fund (WWF), y su declaración como Parque Nacional en 1969 justo después del establecimiento de la
Figura 1. Programación de televisión (izquierda) y clasificación de programas por audiencia (derecha)
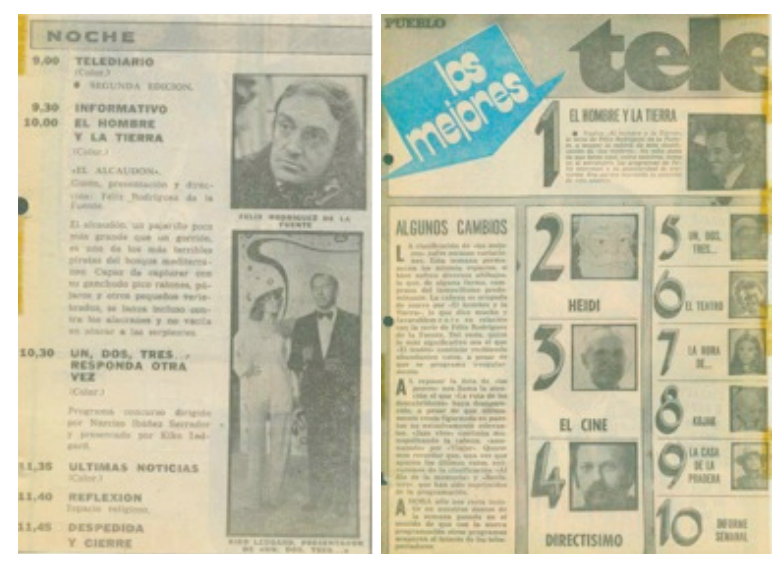

Fuente: Pueblo, 3 de septiembre 1976 (izquierda) y Pueblo 24-30 de abril 1976 (derecha) ${ }^{3}$

sección española del WWF, Adena (1968), cuyo presidente de honor habría de suceder a Franco unos años después como Jefe del Estado, el entonces Príncipe Juan Carlos (Duque, 1977/2004; Valverde, 2004; Ojeda Rivera, González Faraco y López Ontiveros, 2006; Varillas, 2010; véase también en este mismo volumen Camprubí, La naturaleza no existe: conservacionismos y relaciones internacionales en Doñana). Las controversias que Doñana generaba en torno a problemas de contaminación, urbanización, uso del agua y el suelo, y construcción de infraestructuras, en un contexto de creciente preocupación y reivindicación en el ámbito medioambiental aparecían con regularidad en diarios de todo el país. El propio Félix Rodríguez de la Fuente había contribuido decisivamente a su popularización, a través de lujosos reportajes publicados en la revista Blanco y Negro de $A B C(1967)^{4}$, programas de radio dedicados específicamente al Parque $(1975)^{5}$, y con su presencia en artículos relacionados con reivindicaciones medioambientales (figura 2).

Con estas premisas, en este artículo nos proponemos analizar las características técnicas, narrativas y argumentativas de la representación que hace Félix Rodríguez de la Fuente del Parque Nacional de Doñana en estos cuatro capítulos, así como su trascendencia en dos ámbitos distintos pero interrelacionados. En primer lugar, es necesario situar estos documentales en la extensa obra mediática de Rodríguez de la Fuente, que ha sido insistentemente considerada como un punto de referencia crucial para entender las características y consecuencias de los cambios en la construcción y la percepción de la naturaleza y de las ciencias naturales 
Figura 2. Entrevista de Ramón Lobo Leyder a Félix Rodríguez de la Fuente
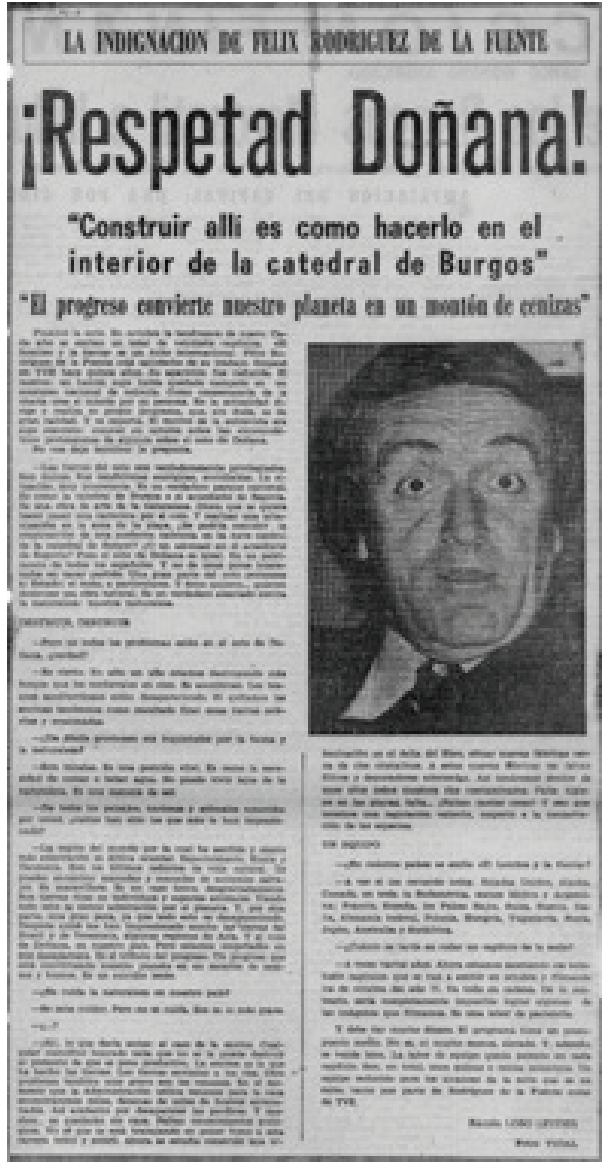

Fuente: La Nueva España, 11 de mayo $1976^{6}$

por parte de la población española en los años $70^{7}$. Con un enfoque centrado en las relaciones entre los seres humanos y su entorno, el amplio espectro de la producción mediática de Félix Rodríguez de la Fuente conformó una suerte de temprano ejercicio trans-media en el que una serie definida de líneas argumentales en torno a la conservación y las ciencias naturales pueden seguirse, y de hecho se retroalimentan, a través de diferentes soportes (Jenkins, 2006; Jenkins, 2010). Sus programas de televisión y de radio, sus libros y exitosas enciclopedias, sus reportajes foto-periodísticos en revistas de gran tirada, así como sus frecuentes colaboraciones, sea en forma de artículos o de entrevistas, en diarios, e incluso sus apariciones en otros tipos de prensa y en formatos de todo tipo, podían consumirse de un modo independiente, si bien siempre iban cargadas de referencias cruzadas. Esta reciprocidad funcionaba evidentemente como un constante reclamo publicitario al resto de la producción, pero también intensificaba y enriquecía el tratamiento de los distintos temas, añadiendo matices y puntos de vista de acuerdo con las características técnicas y narrativas de cada medio (Varillas, 2010) ${ }^{8}$. En este sentido, sus referencias a Doñana fueron recurrentes a lo largo de casi dos décadas, como ya se ha mencionado, de manera que los documentales emitidos en 1979 no se presentaron en un vacío, ni desde el punto de vista de la obra mediática y particularmente televisiva de su autor, ni en lo relativo al Parque y las líneas de argumentación que generaba.

$\mathrm{Y}$, en segundo lugar, y desde el punto de vista exclusivo de la televisión, es necesario ubicar estos documentales, así como El Hombre y la Tierra en su conjunto, en la historia de la televisión sobre historia natural y, en concreto, de la producción de documentales cinematográficos sobre vida salvaje. Este tipo de producciones constituye un género muy peculiar y con frecuencia problemático en relación con la comunicación de las ciencias naturales (Bousé 2000; Dingwall y Aldridge, 2006; Horak, 2006). La educación, el entretenimiento, el periodismo científico-técnico y la ficción se mezclan en estos productos mediáticos no solo como vehículos de comunicación y popularización de las ciencias naturales, sino también, a menudo, para abordar problemáticas medioambientales que los sitúan en espacios política y económicamente muy complejos desde el punto de vista institucional. En este sentido, la obra de Félix Rodríguez de la Fuente en el campo de las ciencias naturales nos permite explorar procesos de generación, circulación y gestión de conocimiento científico-tecnológico en un periodo especialmente convulso de la historia reciente de España (1964-1980), que incluye el fin de la dictadura y el comienzo del régimen democrático. Al igual que ocurría al mismo tiempo en contextos democráticos establecidos, como es el caso de Gran Bretaña y la actividad de la Unidad de Historia Natural (Natural History Unit) de la BBC, no se pueden obviar las crecientes reivindicaciones en el ámbito medioambiental y su particular carga social, política e ideológica a la hora de considerar la producción de documentales sobre la naturaleza (Davies, 2000; Boon, 2008; Boon, 2014; Brockington, 2008; Gouyon, 2011). En los documentales de Félix Rodríguez de la Fuente, y específicamente los dedicados al Parque Nacional de Doñana, que son nuestro objeto de estudio aquí, la meticulosa y, en cierto modo, repetitiva invocación a la sensibilidad hacia la naturaleza en su conjunto, y hacia el Patrimonio Natural en particular, se presentaba como una pieza clave de modernización, adquirida y fundamentada con el estudio y el rigor de las ciencias naturales, en un contexto de intensa (re)definición de identidades (sociales, políticas, culturales) durante la compleja transformación de la dictadura franquista en un régimen democrático. 


\section{EL HOMBRE Y LA TIERRA}

Los documentales de la serie El Hombre y la Tierra comparten características de dos tipos de documentales bien definidos y no necesariamente desligados sobre naturaleza y vida salvaje: las producciones a gran escala y de marca (blue chip), y los documentales conducidos por un presentador (presenter-led) (Bousé 2000; Aldridge y Dingwall, 2003; Dingwall y Aldridge, 2006; Salcedo de Prado, 2008; León, 2010). El Hombre y la Tierra, desde la primera serie realizada en Venezuela (1973-1974), se convirtió en uno de los estandartes de la producción televisiva de calidad para Televisión Española. La empresa ha seguido utilizando el programa con orgullo como reclamo publicitario y ejemplo de excelencia ${ }^{9}$, de manera que El Hombre y la Tierra se ha mantenido a lo largo de los años como un punto de referencia de calidad e identidad en la producción televisiva española. De hecho, en el año 2000, justo 20 años después de que la muerte de su autor interrumpiera su producción, la entonces recién creada Academia de las Ciencias y las Artes de Televisión concedió a El Hombre y la Tierra el premio a la Mejor Producción de la Historia de la Televisión en España (Salcedo de Prado, 2008). En este sentido, la calidad del programa ni tan siquiera es discutida por sus críticos y detractores, que utilizan esta alta valoración como base para la argumentación en su contra, generalmente centrada en que la excesiva identificación de la excelencia de la producción con la autoría exclusiva de Rodríguez de la Fuente oblitera las aportaciones, el rigor y el esfuerzo del resto de los implicados, tanto naturalistas como profesionales del cine y la televisión (Rodríguez Jiménez, 2006). Estas críticas, tanto por parte de ex-colaboradores como de compañeros naturalistas ajenos a la producción mediática de Rodríguez de la Fuente vienen a conformar otro reconocimiento más o menos explícito de esa calidad en términos del consiguiente impacto percibido, sobre todo en relación con el éxito del programa entre el público ${ }^{10}$.

Más allá de estas consideraciones y de los personalismos que habitualmente implican, desde el punto de vista de la historia de la televisión de historia natural, EI Hombre y la Tierra cumple cuatro criterios descritos en lo referido a la definición o cuando menos al estudio crítico de la calidad de este tipo de programas (Wheatley, 2004). En primer lugar, el reconocido esfuerzo de producción por parte de Televisión Española, no solo en los inicios del programa, cuando se puso en marcha la expedición a Venezuela en 1973, sino mantenido a lo largo de los años, en especial con la serie "Ibérica" (Salcedo de Prado, 2008; Varillas, 2010).
Este esfuerzo, en segundo lugar, se correspondió con una apuesta clara por la exportación del programa a otros países, principalmente ante el resultado y el éxito de público de la "Serie Venezolana". Los premios internacionales que pronto empezaron a llegar y el éxito de estas exportaciones permitían por lo menos justificar el mantenimiento del esfuerzo en momentos complejos desde el punto de vista de iniciativas de financiación pública (Salcedo de Prado, 2008) ${ }^{11}$. En cierto modo, Televisión Española jugaba sus bazas en un terreno abonado, puesto que la afluencia de cartas dirigidas a Félix Rodríguez de la Fuente alabando sus programas y, por consiguiente, pidiendo más, no había dejado de crecer desde sus primeras apariciones en televisión en 1964 (Varillas, 2010). Este apoyo por parte de los espectadores se mantuvo y amplió con la llegada a las parrillas de programación de El Hombre y la Tierra. Los espectadores insistían en la calidad y la fuerza del programa incluso cuando dirigían a Rodríguez de la Fuente cartas de protesta, como en el caso de la controversia generada por el capítulo en el que se mostraba de un modo característicamente explícito una cruel matanza de capibaras ( $E$ l rodeo de los Chigüires, emitido el 25 de marzo de 1974). Félix Rodríguez de la Fuente fue siempre consciente de la importancia de este apoyo de los espectadores e hizo un esfuerzo constante por responder a las cartas recibidas con la ayuda de sus sucesivas secretarias. En la polémica por el capítulo de las capibaras, Ángela Minaya, entonces su secretaria (y que aparece en los títulos de crédito de El Hombre y la Tierra como "Secretaria de Dirección"), generó una respuesta "tipo" en la que justificaba la secuencia y su carácter explícito en términos conservacionistas y en la necesidad de reflexionar sobre la relación de los seres humanos con su entorno natural. Esta respuesta contenía, además, una valoración de la indispensable participación de los espectadores en la transformación de la percepción y gestión del Patrimonio Natural a nivel social, político y cultural (véase también en este mismo volumen Tabernero, "La libertad de todos los seres vivos». Naturaleza, ciencias naturales y la imagen de España en la obra de Félix Rodríguez de la Fuente) ${ }^{12}$.

En tercer lugar, es importante señalar el hecho de que el programa comenzó, desde el punto de vista genérico, con una expedición a Venezuela que acentuaba el marcado carácter científico de la empresa (Mitman, 1999; Chris, 2006). Los capítulos de esta primera serie no solo mostraban el quehacer y los resultados del trabajo de los cineastas y naturalistas en lo que atañe a la fauna y el entorno, sino que se adentraron con fuerza en el terreno de la antropología al dedicar 
una buena parte de la producción al pueblo Yanomamo, habitantes del Estado Amazonas al sur de Venezuela $^{13}$. Esta exploración de la vida de los Yanomamos acentuaba las características clásicas del uso del cine como herramienta de investigación científica, por su condición de vehículo de acceso a lo exótico, desconocido e inalcanzable (León, 1999). Los documentales occidentales de corte antropológico, sobre todo aquellos que tienen lugar en contextos en los que también es fundamental el retrato de la fauna, difícilmente pueden eludir, aunque no sea ese su objetivo explícito, la evocación jerárquica, de corte colonial, que inevitablemente conlleva la propia actividad mediática y la accesibilidad que sus características tecnológicas comportan en comparación con la supuestamente poco "avanzada" sociedad que se retrata. Esa apreciación refuerza el énfasis en el rigor científico de los documentales por la dificultad de su realización, tanto técnica como ética (Tabernero, Jiménez Lucena y Molero, 2012; Wheatley, 2013; Tabernero, 2016). En la filmación de los Yanomamos, además, ya no se trataba de utilizar imágenes producidas por otros, como en los programas en los que Félix Rodríguez de la Fuente había ejercido literalmente de profesor desde su despacho (Fin de Semana, Televisión Escolar, Fauna, Aventura y Planeta Azul, entre 1964 y 1973), sino que era él mismo con su equipo el que había ido a asegurar el rigor y la equidad de lo expuesto, y que tenía, ahora sí en primera persona desde el punto de vista técnico, una clara correspondencia con la competencia técnica cinematográfica de ese mismo equipo.

En este sentido, y en cuarto lugar, la medida de calidad del programa giraba invariablemente en torno a la personalidad de Rodríguez de la Fuente, a su imagen, a su celebridad y a su extensa presencia tanto en la narración, con su poderosa voz, y su ya conocida retórica que tanto insistía en la necesaria base científica de lo que se presentaba, como en las imágenes (Varillas, 2010; véase también en este mismo volumen Tabernero, "La libertad de todos los seres vivos». Naturaleza, ciencias naturales y la imagen de España en la obra de Félix Rodríguez de la Fuente; y Tabernero y Varillas, Conservacionismo, ciencia y comunicación. Entrevista a Miguel Delibes de Castro). Entre estas se incluyeron de manera significativa secuencias que documentaban el riesgo personal implícito en el servicio que se prestaba con los programas, en nombre del rigor científico y cinematográfico, de la pasión que una tarea como esta implicaba, y de la coherencia del mensaje. Tal es el caso del capítulo Operación Anaconda, el tercero de la serie, emitido el 18 de marzo de 1974, donde durante el salvamento urgente de unas anacondas por parte del equipo de El Hombre y la Tierra se filmó la mordedura que una de las serpientes propició a Rodríguez de la Fuente. La imagen congelada del incidente se utilizó desde el primer momento en la carátula de presentación de la serie y venía a representar, conjunta y precisamente, a través de la identificación con su autor, el rigor, la profesionalidad, la pasión y la coherencia del programa.

Esta identificación señala la importancia de la segunda tipología de documentales que se superpone a la condición de El Hombre y la Tierra como producción de marca a gran escala: los documentales conducidos por un presentador (presenter-led) (Bousé 2000; Aldridge y Dingwall, 2003; Dingwall y Aldridge, 2006; Salcedo de Prado, 2008; León, 2010). Se ha descrito que este tipo de documentales resulta problemático principalmente por su supuesta carga adicional de subjetividad (relacionada con una línea editorial claramente personalizada), a pesar de que al mismo tiempo se les reconoce una mayor capacidad de atracción y mantenimiento de audiencias, debido al establecimiento de una relación cercana entre la audiencia y una figura de prestigio. De hecho, estos documentales no están necesariamente marginados en las parrillas de programación, como a veces ocurre con los documentales a gran escala, dado que resultan una fuente importante y deliberadamente conjunta de significado (educación), placer (entretenimiento) e identidad (acción, participación). La personalidad del presentador, como garante del rigor científico y personaje cercano que insistentemente, a través de la periodicidad de la serie en la parrilla de programación, entra en el contexto doméstico de la vida cotidiana de las personas, canaliza la imagen de autoridad, incluso con la subjetividad implícita, y por tanto la sensación de certeza que se busca como uno de los objetivos principales en la producción de programas de ciencia para televisión (Collins, 1987; Jones, 2011; Boon, 2014; Florensa, Hochadel y Tabernero, 2014b).

En el caso de El Hombre y la Tierra, todas estas características estaban ya firmemente establecidas por su autor a través de su abundante producción previa. En la celebridad de Rodríguez de la Fuente se combinaban eficazmente diversos atributos y caracteres donde la construcción de los mensajes se hacía paralelamente a la construcción del personaje: su ya mencionada presencia como "profesor" en sus programas de televisión, reforzada por sus iniciativas educativas ${ }^{14}$ o los consultorios en diversas publicaciones ${ }^{15}$; su cercanía, construida a través de su cuidadosa e insistente definición como "Félix, el amigo de los animales" 
o "vuestro amigo Félix" (figura 3), donde el uso del nombre de pila resulta fundamental; su no obstante nunca olvidada condición como "doctor" (figura 3), aunque no se supiera o se tuviera presente necesariamente que el título se correspondía con su condición de médico estomatólogo y no de naturalista; y sus conocidas actividades como activista conservacionista, como en el caso de su influyente papel en Adena, que le permitía participar en actividades de gestión de patrimonio a gran escala y junto a élites políticas y científicas a nivel nacional e internacional.

La construcción trans-mediática que Félix Rodríguez de la Fuente hizo de sí mismo como fuente deliberadamente cercana de autoridad y rigor científicos buscaba una amplia audiencia que diera respuesta a su apasionado mensaje de conservación de la naturaleza. No cabe duda de que Rodríguez de la Fuente era muy consciente de las características de producción y consumo de los medios en los que trabajaba, en concreto, en nuestro caso, de la televisión. La combinación de las características de producción documental de gran escala de El Hombre y la Tierra, con la reiterada asociación en sus capítulos de la calidad y espectacularidad del retrato de la naturaleza con la solidez de la actividad profesional del equipo de naturalistas, servía para reforzar la llamada a la implicación y participación por parte de los espectadores en el espíritu conservacionista. A esto se sumaba, además, la insistente alusión a un impacto tangible de estas actividades profesionales (naturalistas y cineastas) a través del estabalecimiento de la relación directa del programa con estamentos de poder, como el ICONA, y por tanto el Ministerio de Agricultura, que aparecía en un título de crédito exclusivo como cooperador necesario en la

Figura 3. Doctor Rodríguez de la Fuente (izquierda) y Vuestro amigo Félix (derecha)
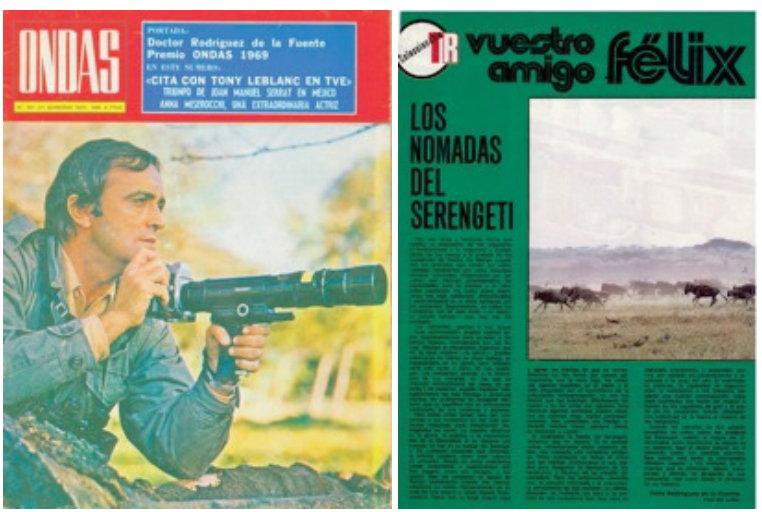

Fuente: Ondas, 1969 (izquierda); TeleRadio, 1975 (derecha) ${ }^{16}$ realización. La respuesta "tipo" generada a partir de las protestas por la crudeza de las imágenes en el capítulo sobre las capibaras, mencionada anteriormente, resume explícitamente todos estos aspectos:

"Comprendo perfectamente su postura ante el dramatismo de las secuencias filmadas en el capítulo de EL HOMBRE Y LA TIERRA "El Rodeo de los Chigüires". Por tal razón me complace darle algunas explicaciones sobre este delicado tema [...] Intencionalmente filmamos las terribles secuencias en toda su crudeza, sin omitir las manifestaciones de dolor o pánico de las víctimas. La razón de esta intencionalidad estriba en el hecho de que la mayor crítica que se puede hacer a estos primitivos procedimientos de caza, es la de mostrarlos en toda su crueldad ante el mundo. Si hubiéramos paliado escenas sangrientas [...] no hubiera desencadenado la repulsa popular. Y pretendemos que esa repulsa sea la que, de alguna mane$r a$, ponga fin a esta matanza anual [...] Creemos que hemos cubierto nuestro objetivo al levantar una ola de indignación. Pero sería totalmente inútil nuestro rigor de documentalistas y la sensibilidad de los públicos, si esa ola de indignación no se canalizara de una manera eficaz a través de Gobiernos y Asociaciones, legalmente reconocidas [...] En ese aspecto estamos a su entera disposición en la Secretaría General de Adena." (Carta a M.J.C.R., fechada en abril de 1974. Énfasis añadido) $)^{17}$.

Por su parte, Rodríguez de la Fuente recibía cientos de cartas con preguntas, sugerencias y peticiones de ayuda en cuanto a qué y cómo hacer con respecto a la conservación de la naturaleza y de la profesión de las ciencias naturales. Es por esto que se habla repetidamente de un antes y un después de la obra de Félix Rodríguez de la Fuente, tanto en el mundo del conservacionismo y el ecologismo, como en el desarrollo de las ciencias naturales como disciplina en España ${ }^{18}$. Más allá de este tipo de apreciaciones, difícilmente contrastables, la extraordinariamente abundante correspondencia entre Rodríguez de la Fuente y sus públicos, mantenida de forma ininterrumpida a lo largo de su carrera mediática, ilustra la reciprocidad entre las transformaciones de prácticas de comunicación por parte de los usuarios de medios de comunicación de masas, las instituciones que finanacian y controlan estos medios, y los comunicadores que los trabajan y desarrollan, independientemente de objetivos educativos, formativos o adoctrinadores más o menos explícitos. En un contexto en el que las reivindicaciones medioambientales se utilizaban como estandarte $y$ campo de batalla en el seno de corrientes que pedían 
cambios sistémicos mucho más amplios a nivel internacional, y que en España tenía unas características especiales relacionadas con el ocaso de la dictadura y la exigencia de cambios a nivel político, social, económico y cultural, la conjunción de cercanía, autoridad, activismo y rigor en la producción mediática de Rodríguez de la Fuente, y sobre todo en su buque insignia, El Hombre y la Tierra, articuló el mensaje conservacionista y su construcción del Patrimonio Natural en términos de necesaria modernización (Tabernero, 2012; véase también en este mismo volumen Tabernero, "La libertad de todos los seres vivos». Naturaleza, ciencias naturales y la imagen de España en la obra de Félix Rodríguez de la Fuente). Además, el esfuerzo de Televisión Española con esta serie coincidió con un periodo de transformación de la propia televisión pública con objetivos de mejora y modernización en términos cualitativos y cuantitativos (Ortega Gálvez y Albertos, 1998; Rueda Laffond y Coronado Ruiz, 2010) ${ }^{19}$. El Parque Nacional de Doñana era una pieza clave en el centro de este contexto. La realización de cuatro documentales dedicados al Parque en El Hombre y la Tierra y su emisión en 1979, 10 años después de su establecimiento, justo en el momento de la consolidación de la transformación socio-política de España, con la Constitución de 1978 recién aprobada en referéndum, no hacía sino insistir en la necesidad del cambio modernizador más allá de la tangibilidad del cambio de régimen.

\section{EL ESPECTÁCULO DE LA CONSERVACIÓN}

Los documentales sobre al Parque Nacional de Doñana forman parte de la "Serie Ibérica" de El Hombre y la Tierra ${ }^{20}$. Esta serie, mediante su foco en la fauna de la península, trasladaba las características científicas y espectaculares del género, introducidas en la primera temporada desarrollada en la Amazonia venezolana, al contexto proximal de los espectadores españoles. De pronto, lo exótico, lo aparentemente inaccesible, lo desconocido, se situaba, como quien dice, en el patio de atrás. No era ni mucho menos la primera vez que Rodríguez de la Fuente se fijaba en el contexto español: su interés por la fauna ibérica se fundamentaba en su propia experiencia como cetrero y defensor de las aves de presa frente a las Juntas Provinciales de Extinción de Animales Dañinos ${ }^{21}$; en su concienzuda exploración del mundo de la etología a partir no solo de la cetrería sino también de su ampliamente publicitada pasión por el lobo ibérico ${ }^{22}$; y en las intersecciones de su actividad como naturalista, activista y comunicador con su colaboración con el Ministerio de Información y Turismo y directamente con su titular, Manuel Fraga, en la década de los 60, en campañas destinadas a la promoción del Turismo (Varillas, 2010; véase también en este mismo volumen Tabernero, "La libertad de todos los seres vivos». Naturaleza, ciencias naturales y la imagen de España en la obra de Félix Rodríguez de la Fuente). Significativamente, el estreno de la "Serie Ibérica" de El Hombre y la Tierra en 1975 coincidió con el comienzo de la publicación y venta por fascículos de la Enciclopedia Salvat de la Fauna ibérica y europea (1975-1978), que, tras el éxito comercial de la Enciclopedia Salvat de la Fauna (1970-1973), dejaba atrás la gran fauna exótica internacional para centrarse también en los animales autóctonos.

Todo este esfuerzo articulaba, desde el punto de vista del mensaje conservacionista y sus activismos, y sin perder la insistencia en el rigor científico como base insustituible, la necesidad de centrarse en lo local, de comenzar por lo que se tiene a mano, por lo que es significativamente accesible. En un contexto de reivindicaciones medioambientales a nivel internacional que funcionaban como trasunto de demandas más amplias de cambio sistémico, el enfoque local de Rodríguez de la Fuente durante el final de la dictadura insistió en la necesidad de un cambio de perspectiva en la gestión del Patrimonio Natural, precisamente con el rigor científico como adalid de modernización. En este sentido, por un lado, si bien Rodríguez de la Fuente mantuvo siempre escrupulosamente un discurso alejado del alegato explícitamente político, no excluía, cuando lo consideraba necesario, expresar reivindicaciones dirigidas directamente a la Administración ${ }^{23}$. Y por otro, además, la "Serie Ibérica" le sirvió para subrayar, aún más si cabe, el trasfondo científico de su empresa. El establecimiento de lo que literalmente funcionó como un estudio al aire libre para la producción de los capítulos de la serie en Pelegrina (Guadalajara), a pocos kilómetros de Madrid (Rodríguez Jiménez, 2006), y los desplazamientos "cortos" a distintos lugares de la península en comparación con el esfuerzo previo en Venezuela y el posterior en Canadá, es decir, la propia condición de cotidianeidad que implicaba la localidad de los temas, propició la transformación transitoria del carácter de los documentales.

Sin abandonar un estilo predominantemente expositivo que, de hecho, contribuía a considerar lo local bajo la perspectiva del documental de gran escala, la condición expedicionaria quedaba relegada a un segundo plano. Sin embargo, se reforzó la condición del programa como labor científica. La aparición del pro- 
pio Félix Rodríguez de la Fuente en los programas en calidad de científico siguió siendo habitual. A veces, esta condición de científico se mencionaba explícitamente, siempre en torno a su definición como "doctor". Otras veces, se insinuaba con las referencias que daba al trabajo de otros científicos y naturalistas y su relación directa con su actividad, sus observaciones y el contenido de los capítulos. Y muchas veces se reforzaba con la filmación de la actividad que él y sus colaboradores, naturalistas y cineastas, desarrollaban en y para el capítulo, de manera que el retrato del ejercicio "local" de estas profesiones se convirtió en uno de los motivos narrativos principales. La representación de una imagen específica de la naturaleza quedaba ligada así a la configuración de una imagen también muy concreta de las ciencias naturales y de su incidencia en la construcción y gestión del Patrimonio Natural, es decir, en este caso, al tratarse de localizaciones peninsulares, del medio en el que se desarrollaban las vidas de los espectadores. A esto se añadía la referencia constante a la captación de imágenes "por primera vez", generalmente acerca de comportamientos, lo que reforzaba la mencionada correspondencia entre la calidad del producto cinematográfico con la base y la autoridad científica que sustentaba lo filmado. En algún caso, se llegaba más allá al dotar a las filmaciones del carácter demostrativo de una investigación propiamente dicha. La identificación de lo local y su relación con la vida cotidiana de las personas con investigaciones científicas de renombre internacional se llevó al extremo en un capítulo bien conocido y muy popular de la serie, El buitre sabio ${ }^{24}$. Este capítulo, tal y como está narrado (en texto e imágenes), más que un documental sobre alimoches en la península, formaba parte del planteamiento, la planificación, el desarrollo y el resultado de un experimento etológico para esclarecer si cierto comportamiento (la rotura de huevos de avestruz con la ayuda de piedras como herramientas por parte de los alimoches) estaba determinado genéticamente o era aprendido. Las ramificaciones de este experimento llegaban hasta artículos publicados en revistas de reconocido prestigio científico y divulgativo internacional como Nature y National Geographic, por personajes tan conocidos como Jane Goodall y Hugo van Lawick (Alcalá-Lorente y Tabernero, 2014).

Los cuatro documentales sobre el Parque Nacional de Doñana llegaron en lo que, en definitiva, sería el periodo final tanto de la "Serie Ibérica" como del programa, no porque así estuviera planificado, sino, como se sabe, por el desafortunado accidente en el que murieron Rodríguez de la Fuente, dos de sus colaboradores más próximos, Teodoro Roa y Alberto Ma- riano, y el piloto de la avioneta siniestrada, Warren Dobson. Doñana era Parque Nacional desde $1969^{25}$ y, de hecho, tal y como menciona el propio Rodríguez de la Fuente en la conclusión de los cuatro documentales, se le acababa de dotar con un régimen jurídico especial de reclasificación ${ }^{26}$. En este sentido, los rodajes en Doñana no habían estado exentos de dificultades, precisamente por su condición como zona protegida y bajo la gestión de la Estación Biológica establecida en 1965 (véase en este volumen Camprubí, La naturaleza no existe: conservacionismos y relaciones internacionales en Doñana). Estas dificultades provocaron, en ocasiones, pequeñas discordias entre dos buenos amigos y valedores del Parque, el propio Rodríguez de la Fuente y José Antonio Valverde, cuando este último era aún director de la Estación. Una carta enviada por Rodríguez de la Fuente a Valverde en 1974, cinco años antes del montaje final y la emisión de los cuatro capítulos, además de mostrar la naturaleza de estas dificultades, nos permite apreciar la importancia que Rodríguez de la Fuente otorgaba a la producción de un documental sobre Doñana como parte esencial y complementaria a la labor de la Estación y la función del Parque (figura 4$)^{27}$.

En cualquier caso, Rodríguez de la Fuente finalmente consiguió realizar estas películas que consideraba esenciales dentro del planteamiento de la "Serie Ibérica" de El Hombre y la Tierra. Desde un punto de vis-

Figura 4. Fragmentos de la carta escrita por Félix Rodríguez de la Fuente a José Antonio (Tono) Valverde, fechada el 25 de mayo de $1974^{28}$

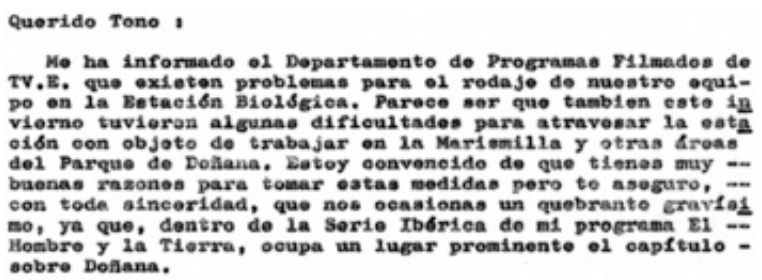

Croo que la tolevision ha solieitado, fla hace wo a quinee dias, tu oportuna autorigaelon para rilaar on a oonooer tu respuesta, para no 1 malsouirno on tomas e la televiaion.

S1n enbargo, we Euotarfa manifestarte que la sorie E1 Hombre y la Tiorra ha tonido un Exito de erftica, de

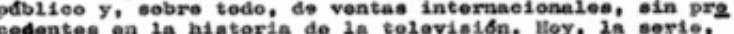
que gans is Gran Porla Hired de Milan, esta praetioerionte

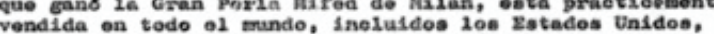

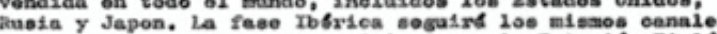
do vesta $y$ eonaidero my pooitivo para la Eataeidn B1018 riea una tan amplia divulgaeion de ou inportaneia oeoleGiea. Ne neoseito reoordarte la urgeneia de tu respuesta,
on eualequier sentido, pare realizar nuestras filaaelones. 
ta estrictamente formal, y a pesar de su emisión en cuatro entregas, lo cual contribuyó a subrayar la importancia del Parque, no es difícil percibir el resultado como la realización de un solo documental montado posteriormente, sobre el material rodado, en esas cuatro partes:

"Estos cambios estacionales en el Parque Nacional de Doñana son los que nos han aconsejado describir su biología en cuatro capítulos que se adaptan más o menos someramente a las cuatro estaciones del año." (El Parque Nacional de Doñana I. La invernada de los gansos).

La estructura en cuatro capítulos refuerza sus características de retrato espectacular de grandes espacios y de su fauna. No obstante, el estilo es marcadamente contemplativo y está asociado a la preponderancia del valor ornitológico de las marismas en el que se había fundamentado su transformación en zona protegida, centro de investigación biológica y, finalmente, Parque Nacional (Valverde, 2004; Varillas, 2010; véase también en este mismo volumen Camprubí, $L a$ naturaleza no existe: conservacionismos y relaciones internacionales en Doñana). Casi todo el metraje se centró en la contemplación de aves y de su comportamiento en su paso por Doñana, y reiteradamente, en un número concreto de especies (espátulas, ánsares, garzas y águilas imperiales). Los largos segmentos sobre estas aves se entretejieron con fragmentos más cortos dedicados a otras especies (patos, flamencos, cigüeñas); a una minuciosa descripción de paisajes, sobre todo de dunas y marismas; la constatación de la actividad humana implicada en la vida del Parque, como en el caso de las menciones a la ganadería y su interacción con la fauna salvaje (capítulos III y IV); y puntuaciones de distinto carácter y envergadura a través de la atención a otros animales, fundamentalmente mamíferos. A este respecto, las breves secuencias con el meloncillo, el lince y los jabalíes (capítulos I, III y $I V)$, y los segmentos bastante más largos dedicados a gamos y venados (capítulos I, III y IV), funcionaban como trasunto de la gran fauna de los documentales expositivos a gran escala de las grandes cadenas y productoras televisivas internacionales. Del mismo modo se conducía la única aunque suntuosa filmación de un nutrido grupo de buitres leonados dando cuenta de un cadáver (capítulo IV), que remite directamente a secuencias propias de otras latitudes más exóticas y, si se quiere, espectaculares.

Este reclamo postrero de espectacularidad genérica bien puede interpretarse, en términos cinematográficos, como un intento deliberado de situar el Parque en un contexto de importancia global en cuanto a sus tesis conservacionistas. Este objetivo se hacía explícito con las repetidas menciones a otros parajes (en Europa, África y el Caribe) en relación con las costumbres migratorias de las aves que utilizan las marismas del Gualdalquivir en sus largos periplos, y junto a las que se enfatizaba su importancia y su fragilidad:

\footnotetext{
"Tan solo hace cinco años, la población de ánsares invernantes en la marisma del Guadalquivir se aproximaba a los veinte mil especímenes. Se especula con distintas teorías para explicar el gran crecimiento de los gansos invernantes. Se piensa que, por un lado, las medidas proteccionistas que se toman en los países donde crían estas aves son cada día más estrictas. Por otro lado, han desaparecido dramáticamente los espacios palustres en Europa mediterránea por donde los ánsares comunes podían distribuirse [...] si las condiciones naturales de la marisma del Guadalquivir se alteran por contaminación, por degradación o por cualquier otro proceso antropógeno, toda la población ornítica de estas aves en Europa occidental se encontraría en gravísimo peligro. Este es un importantísimo matiz de la marisma del Guadalquivir [...]" (El Parque Nacional de Doñana I. La invernada de los gansos).
}

La conjunción de la reivindicación de la importancia y la fragilidad del Parque con imágenes cuyo objetivo evidente es la belleza y la espectacularidad es especialmente obvia en la conclusión de esta mini-serie sobre el Parque. En la solemne y extensa contemplación final de las evoluciones del vuelo de grandes bandadas de flamencos, con el inevitable toque de exotismo que estas aves incorporan de cara a los espectadores peninsulares, y sobre los que no se dice nada desde un punto de vista científico (ya había hablado de un modo más técnico sobre los flamencos al principio de este mismo capítulo $(V)$, Rodríguez de la Fuente hizo una semblanza histórica de Doñana: "Aprovechamos nosotros los bellos vuelos de flamencos rosados para hacer un corto y obligado comentario histórico del Parque Nacional de Doñana" ${ }^{29}$. En su alocución se combinaron eficazmente detalles de la historia de España con las conexiones internacionales a nivel político y científico, incluido también el papel en este terreno del Consejo Superior de Investigaciones Científicas, que establecían el valor indiscutible, por contrastado a través de múltiples fuentes, del Parque y de las actuaciones de protección sobre la zona:

"Cuando ilustres familias de la región [...] se preocupan ya de la conservación de este privilegiado enclave, el doctor Valverde, entonces joven naturalista, es capaz de interesar a un grupo de ornitólogos 
ingleses, capitaneados por el premio Nobel Sir Julian Huxley, para que realicen en el año 1957 una expedición científica al coto de Doñana. Como consecuencia de su informe, el recién creado World Wildlife Fund Internacional organiza una campaña de recaudación de fondos en toda Europa para comprar una parcela del coto que regala posteriormente al Estado Español y da nacimiento a la Estación Biológica de Doñana, dependiente del Consejo Superior de Investigaciones Científicas." (EI Parque Nacional de Doñana IV. La ronca de los gamos).

En ese repaso no faltó una alusión más (había incluido otras en los tres capítulos anteriores) a la necesidad de una revisión de las políticas medioambientales gubernamentales: "Posteriormente, el World Wildlife Fund, a través de su representación española, Adena, adquiere también la marisma de Guadamar. Paralelamente el Ministerio de Agricultura decreta la creación del Parque Nacional de Doñana, de insatisfactorios límites y complejo estatuto jurídico según los naturalistas." ${ }^{30}$

En este sentido, toda vez que en 1979 el prestigio del programa y la competencia cinematográfica y científica de su autor y su equipo estaban más que establecidos, resulta significativo el carácter casi exclusivamente contemplativo de estos cuatro documentales así como la ausencia de Rodriguez de la Fuente en la pantalla. Estos dos detalles enfatizaban el valor paisajístico y por tanto contribuían a reforzar y matizar el mensaje conservacionista, añadiendo el componente lúdico y saludable de la idea del Patrimonio Natural (véase en este mismo volumen Casado, Patrias primitivas. Discursos e imágenes de la naturaleza en el primer conservacionismo español) al marcado carácter científico de la serie. Rodríguez de la Fuente incluso introdujo una exhortación a este respecto al referirse a ciertos comportamientos de las águilas imperiales: "Retiran las águilas imperiales los restos que podrían contaminar los nidos, dando con ello una lección al hombre que tantas inmundicias abandona sobre los campos, incluso en los Parques Naturales." ${ }^{31}$

Sin embargo, el guión de los capítulos sobre Doñana situaba al espectador en la posición del ornitólogo observador y estudioso de aves, cuyo carácter científico se enfatizaba por la habitual mención al equipo de naturalistas y cineastas que tenían la suerte de encontrarse con ciertas escenas. La reiteración anteriormente mencionada de secuencias sobre unas especies concretas, si bien era producto del montaje con respecto a las cuatro estaciones, reflejaba también, en cierto sentido, la parte tediosa del trabajo del naturalista. El uso de la primera persona del plural, 'nosotros', contribuía a la identificación de los espectadores con el equipo científico y técnico, en un juego en el que estos podían sentirse primera o tercera persona casi simultáneamente. Este hábil juego retórico, utilizado a lo largo de toda la realización de El Hombre y la Tierra, reforzaba el mensaje conservacionista en términos de rigor, esfuerzo y espectacularidad, al convertir al espectador en partícipe tanto del trabajo cinematográfico como de los descubrimientos y comprobaciones de los naturalistas sobre el terreno ${ }^{32}$.

La ausencia de Félix Rodríguez de la Fuente o de miembros de su equipo en la pantalla, además, difuminaba la subjetividad propia del género documental conducido por un presentador. Esta ausencia forzaba, en cierto sentido, y a pesar de la narración característica que era marca de la casa, pero sin olvidar el uso de expresiones de carácter explícitamente científico, un cierto distanciamiento como reclamo a la independencia y contrastado valor de los argumentos presentados ${ }^{33}$. De este modo, la identificación de los espectadores se remitía aún más poderosamente a la mencionada combinación de los argumentos científicos con la competencia y espectacularidad cinematográficas.

\section{CONCLUSIÓN: ACTIVISMO DESDE EL SOFÁ}

La estructuración de la narración como un ciclo de vida en el que 'el ser vivo' es el Parque en su conjunto enfatizaba genéricamente el tema de la lucha por la supervivencia (Scott, 2003; Salcedo de Prado, 2008; Cabeza San Deogracias y Mateos-Pérez, 2013), y consecuentemente la relación establecida inequívocamente por la narración entre el valor del Parque y su fragilidad. Considerando las implicaciones obvias de este planteamiento en relación con la ecología, como disciplina científica, pero también, sobre todo en el contexto de la emisión, como fuente de reivindicaciones de corte social, político y cultural, el análisis del ejercicio mediático que supuso la realización y emisión de los capítulos sobre Doñana (o, en su conjunto, de El Hombre y la Tierra) no puede obviar su ubicación en la parrilla de programación. Como ya se ha dicho, El Hombre y la Tierra gozó durante la mayor parte de su emisión original de un puesto privilegiado, el prime time nocturno de los viernes. Esta ubicación estaba indudablemente relacionada con la condición del programa como estandarte de calidad de Televisión Española y con la respuesta marcadamente favorable del público tanto hacia el programa como hacia su autor. Pero también suponía tanto un desafío para 
la televisión pública española, por otra parte compartido con otras instituciones mediáticas internacionales, en lo que se refiere a difusión de contenidos de carácter científico (Boon, 2008; Boon, 2014; Gouyon, 2011; LaFollette, 2002; LaFollette, 2012), como una estrategia deliberada. En un contexto en el que solo había dos canales públicos disponibles para elegir, y en el que la llamada primera cadena acaparaba con creces el mayor porcentaje de audiencia, El Hombre y la Tierra se situaba en este canal entre los programas de información y entretenimiento de referencia de la época: la Segunda Edición del Telediario, y, durante importantes periodos de su emisión, Un, dos, tres... responda otra vez, otro programa de marca para Televisión Española en lo que a recursos, popularidad y proyección internacional se refiere. Es decir, el programa de Félix Rodríguez de la Fuente ocupaba, durante el periodo de máxima audiencia televisiva de la semana, el lugar reservado a la educación en la conocida tríada de objetivos y funciones socio-culturales de los medios de comunicación de masas de consumo doméstico: información, educación y entretenimiento (Dugan, 2014; Florensa, Hochadel y Tabernero, 2014b; Guzmán y Tabernero, 2016) ${ }^{34}$. En este sentido, cabe señalar también su correspondencia en cuanto a ubicación en la parrilla de programación con otro programa de referencia en términos de calidad para Televisión Española, que es de hecho hoy en día el más longevo (se emite desde 1973), y también dedicado al género documental, si bien en este caso de corte informativo social, político y cultural: Informe Semanaß35. Este programa ha ocupado durante la mayor parte de su historia la misma franja horaria en la otra gran noche del prime time, la de los sábados, entre la mencionada Segunda Edición del Telediario y, en este caso, un largometraje, una serie o un magazine.

Los capítulos sobre Doñana no coincidieron con el programa de Narciso Ibáñez Serrador en la parrilla. El espacio dedicado al entretenimiento estaba ocupado por una serie norteamericana de ciencia ficción, Investigación Ovni (Project UFO, 1978-1979) ${ }^{36}$. Curiosamente también, entre el informativo y El Hombre y la Tierra se emitía entonces un popular programa de educación vial, La segunda oportunidad (19781979) ${ }^{37}$, dirigido por Paco Costas, periodista especializado en el mundo del motor. El planteamiento de este programa combinaba un carácter abiertamente didáctico con la espectacularidad de los accidentes filmados con la ayuda de un especialista que también llegó a ser muy popular, Alain Petit. Así, con esta ubicación, y a través del relato del ciclo vital en el Parque, estos documentales transmitieron una celebración de la lucha por la definición y conservación del Patrimonio Natural, cuyo significado se articulaba a través de la cuidada representación conjunta de la naturaleza y del ejercicio científico y técnico de las profesiones de naturalista y cineasta. Este discurso se correspondía con las funciones del Parque especificadas en la Ley de reclasificación mencionada anteriormente:

"Dicho régimen jurídico especial se orienta a proteger la integridad de la gea, fauna, flora, aguas y atmósfera y en definitiva del conjunto de los ecosistemas del Parque Nacional de Doñana, así como sus valores histórico-artísticos, y a promover la investigación y la utilización en orden a la enseñanza y disfrute del Parque Nacional, en razón de su interés educativo, científico, cultural, recreativo, turístico y socioeconómico." (Ley 91/1978. Boletín Oficial del Estado 11; 12 de enero de 1979, p. 813).

El tratamiento genérico, estético y narrativo de los documentales, la autoridad mediática y científica establecida de su autor, y el apoyo institucional explícito subrayaron precisamente el "interés educativo, científico, cultural, recreativo, turístico y socioeconómico" que quedaba claro en la Ley.

La respuesta masivamente favorable por parte de los espectadores y mencionada anteriormente con respecto a El Hombre y la Tierra ha permitido que se piense en este programa como motor de cambios en un momento histórico especialmente complejo (Araújo, 1990; Pou, 1995; Ramos Cumplido, 2001; Rodríguez Jiménez, 2006; VV.AA., 2006; Salcedo de Prado, 2008; Varillas, 2010). Nos parece lícito argumentar que El Hombre y la Tierra en su conjunto aportó un significativo componente científico-técnico a los procesos de transformación social, política y cultural de la España de esos años. En un periodo caracterizado también por una progresiva saturación de la vida cotidiana de las personas con medios de comunicación, la estrategia trans-mediática de Rodríguez de la Fuente no solo resultaba eficaz, sino que se situaba poderosamente en el centro de las reivindicaciones en el ámbito medioambiental, sus conexiones con otro tipo de reivindicaciones, y sus traducciones a nivel político, en su uso como reclamo electoral, y en la respuesta institucional, en el contexto del cambio de régimen (Varillas, 2005; Varillas, 2010). Y todo ello, como ocurría concretamente en el caso de Doñana, en clave de definición no exenta de controversia del Patrimonio Natural como bandera de una necesaria y esperada modernización del Estado y de su imagen, donde el componente científico-técnico estaba frecuentemente ligado, y entre otros aspectos y como hemos visto, a 
la definición y contextualización de España en un escenario global (véase en este mismo volumen Tabernero, "La libertad de todos los seres vivos». Naturaleza, ciencias naturales y la imagen de España en la obra de Félix Rodríguez de la Fuente):

"Por consiguiente [...] el Parque Nacional de Doñana constituye un auténtico desafío para el Estado español [...] Mucho se ha polemizado acerca del Parque Nacional de Doñana. Su extensión antigua, cuando se creó la reserva, era de treinta y siete mil hectáreas. Después del reciente proceso de reclasificación, después de la reciente aprobación de la ley de Doñana, ha crecido a cuarenta y ocho mil cuatrocientas hectáreas de Parque, y setenta y tres mil doscientas si se tiene en cuenta la zona de pre-parque. Pensamos que con estas medidas legales se garantiza, al menos administrativamente, el futuro de este emporio biológico español [...]". (El Parque Nacional de Doñana I. La invernada de los gansos).

En este sentido, estos documentales nos llevan inevitablemente al problema de la educación a través de los medios de comunicación de masas y su relación con el entretenimiento $y$, por tanto, con la vertiente necesariamente comercial de los productos mediáticos. Estas cuestiones se han discutido insistentemente a lo largo del siglo XX y, como mínimo desde la difusión masiva del uso de la radio en el medio doméstico en los años 20, casi siempre en conexión con discursos de modernización no solo centrados en los contenidos y su diseño, sino en la concepción científico-técnica de los propios medios (Collins, 1987; Silverstone, 1994; Thompson, 1995; Boon, 2014; Florensa, Hochadel y Tabernero, 2014a; Florensa, Hochadel y Tabernero,2014b; Lehmkuhl, 2014; Úbeda, 2014; Guzmán y Tabernero, 2016). Desde el punto de vista del estudio de los mecanismos (discursos y prácticas) de circulación de conocimiento científico a través de medios de comunicación, no cabe duda de que producciones como El Hombre y la Tierra son una fuente esencial a la hora de pensar en los procesos de producción y gestión de este conocimiento (Galison, 2014).

Este programa constituyó la culminación de un proyecto mediático que Rodríguez de la Fuente (se) planteó a mediados de la década de los 60 (véase en este mismo volumen Tabernero, "La libertad de todos los seres vivos». Naturaleza, ciencias naturales y la imagen de España en la obra de Félix Rodríguez de la Fuente). La intención era decididamente didáctica, pensando en la educación y en las ciencias naturales como el factor modernizador clave para generar un cambio de mentalidad en la población en conjunto, incluidas las instituciones, sobre el Patrimonio Natural. Sin embargo, el resultado, en medio del esfuerzo trans-mediático descrito, buscaba abiertamente involucrar a los espectadores en una tarea colectiva de protección y conservación de la naturaleza que aún debía llevarse a cabo. Esta llamada a la participación constituía el colofón de esa intención educativa y modernizadora y se construía en torno a la combinación de muy diversos factores no obstante relacionados: en primer lugar, la insistencia en el enfoque científico de la argumentación en combinación con la cercanía de lo narrado, de acuerdo con esta base, en las series ibéricas (en las revistas Blanco y Negro y La Actualidad Española; en la segunda enciclopedia que dirigió para la editorial Salvat; en la radio; y en televisión, particularmente en esta "Serie Ibérica" de El Hombre y la Tierra).

En segundo lugar, estos planteamientos se traducían en acciones concretas que se materializaban como consecuencia del empeño por mostrar la labor de los naturalistas implicados en la serie, así como en la búsqueda de la identificación del espectador con estas actividades a través de la labor de los cineastas, que producían imágenes extraordinarias al tiempo que eran espectadores de excepción del trabajo de los primeros. La combinación de estas herramientas técnicas, narrativas y argumentativas se traducía, en los programas, en la transmisión de una sensación de posibilidad que después se reflejaba en las cartas que Rodríguez de la Fuente recibía y en las que muchos niños y jóvenes de la época (o sus padres) preguntaban qué había que hacer o estudiar para ser, y por tanto hacer, como él, o bien le ofrecían directamente su colaboración (véase en este mismo volumen Tabernero, "La libertad de todos los seres vivos». Naturaleza, ciencias naturales y la imagen de España en la obra de Félix Rodríguez de la Fuente).

En tercer lugar, esta sensación, creada a partir del espíritu activista conservacionista de su autor, si bien se situaba dentro del viejo objetivo de las iniciativas de circulación de conocimiento científico en cuanto a la intención de crear vocaciones en el mundo de la ciencia, sin duda encontraba el terreno sembrado en un contexto en el que, en pleno cambio de régimen, el activismo ecologista cobraba cada vez más protagonismo político (en la calle y a nivel institucional) en la construcción de un Estado que prometía ser, al menos aparentemente, diferente.

En este contexto, y en cuarto lugar, la conexión de Rodríguez de la Fuente con sus públicos, a través de esas cartas que recibió ininterrumpidamente durante más de una década, provocaba que este fuera muy 
consciente de las inquietudes y expectativas de la población española a muy diferentes niveles, que abarcaban desde la vida cotidiana de las personas hasta los intereses de las grandes empresas y las instituciones que ostentaban el poder. La combinación de estos factores socio-culturales se transformaba en llamadas explícitas a la participación de los espectadores que estaban viendo los programas desde el sofá de sus casas. Félix Rodríguez de la Fuente reflejó explícitamente todas estas circunstancias e intenciones en la secuencia final del cuarto capítulo dedicado al Parque Nacional de Doñana. En medio de su repaso de la historia de las marismas del Guadalquivir y con los vuelos de los flamencos como telón de fondo, relacionó la Ley recién aprobada con la iniciativa conservacionista y ecologista colectiva, expresando su alegría en nombre de su equipo pero utilizando esa primera persona del plural con la que ha buscado activamente la identificación de los espectadores:

"Pero la inquietud popular proteccionista nacida en los últimos años y expresada a través de asociaciones privadas, grupos ecologistas, e incluso partidos políticos, sugiere al ICONA el planteamiento, en el seno de la Comisión Interministerial de Medio Ambiente, de un proyecto de reclasificación legal del Parque, en el que colaboran no solo los científicos y naturalistas, sino tam-

\section{NOTAS}

1. El primer capítulo de El Hombre y la Tierra, correspondiente a la "Serie Venezolana", que llevaba el título del propio programa, se emitió el 4 de marzo de 1974. Y el último capítulo, Iditarod (1000 millas sobre hielo) II, correspondiente a la "Serie Canadiense", se emitió el 20 de junio de 1981, más de un año después de la muerte de Félix Rodríguez de la Fuente, el 14 de marzo de 1980, precisamente durante el rodaje de esta última serie. La "Serie Ibérica" comenzó a emitirse el 21 de marzo de 1975, con el capítulo Los prisioneros del bosque I, y terminó el 7 de diciembre de 1979, con el capítulo Al borde de la extinción III. En mayo y junio de 1981, se emitieron 6 capítulos adicionales, realizados por Joaquín Vera y escritos por Joaquín Araújo, que funcionaron como coda y también como homenaje al creador de la serie. Los cuatro capítulos sobre el Parque Nacional de Doñana llevaron por títulos El Parque Nacional de Doñana I. La invernada de los gansos http://www. rtve.es/alacarta/videos/el-hombre-y-la-tierra/hombre-tierrafauna-iberica-parque-nacional-donana-1/1459049/; El Parque Nacional de Doñana II. El paraíso de las garzas http://www. rtve.es/alacarta/videos/el-hombre-y-la-tierra/hombre-tierrafauna-iberica-parque-nacional-donana-2/1459051/; El Parque Nacional de Doñana III. Viajeros africanos http://www.rtve.es/ alacarta/videos/el-hombre-y-la-tierra/hombre-tierra-faunaiberica-parque-nacional-donana-3/1460090/; El Parque Nacional de Doñana IV. La ronca de los gamos http://www.rtve.es/ alacarta/videos/el-hombre-y-la-tierra/hombre-tierra-fauna- bién numerosos organismos de la Administración. Cristalizan tantos esfuerzos en la promulgación de la Ley del Parque Nacional de Doñana, aprobada por la Cortes el 28 de diciembre de 1978. Y nos llena de alegría a todos cuantos hacemos El Hombre y la Tierra coincidir con esta fecha histórica en la realización del documental que trata de sintetizar, en cuatro capítulos, la prodigiosa biología de nuestro gran Parque Nacional." (El Parque Nacional de Doñana IV. La ronca de los gamos).

\section{AGRADECIMIENTOS}

Esta investigación forma parte del proyecto HAR201236204-C02-02 (Scientific authority in the public sphere in 20th century Spain), financiado por el Ministerio de Economía y Competitividad; del proyecto 2014 SGR 01410 (History of Science, Technology and Medicine in Modern Catalonia, 18th-20th centuries), financiado por la Agència de Gestió d’Ajuts Universitaris i de Recerca de la Generalitat de Catalunya; y ha sido realizada con el apoyo de la Fundación Félix Rodríguez de la Fuente. Los autores agradecen especialmente a Odile Rodríguez de la Fuente y al personal de la Fundación Félix Rodríguez de la Fuente las facilidades de acceso y consulta del archivo personal de Rodríguez de la Fuente. También quieren agradecer a Jorge Molero Mesa su lectura crítica y sus sugerencias. iberica-parque-nacional-donana-4/1460093/. Se emitieron los días 2, 9, 16 y 23 de marzo de 1979, respectivamente (Ministerio de Educación, Cultura y Deporte / Instituto Nacional de Tecnologías Educativas y de Formación del Profesorado, en adelante MECD/INTEF, 2006a; MECD/INTEF, 2006b). [Radiotelevisión Española. 30 años sin Félix. El Hombre y la Tierra. Fecha de consulta para todos los vídeos: 5 de agosto de 2015].

2. La emisión de El Hombre y la Tierra coincidió en la parrilla de programación con la segunda etapa del programa de Ibáñez Serrador, que estuvo en antena desde marzo de 1976 hasta enero de 1978. (MECD/INTEF, 2006b).

3. Archivo Fundación Félix Rodríguez de la Fuente (en adelante FFRF), c. 12.

4. Los dos reportajes exclusivos son: "Fauna Ibérica 13. La Estación Biológica de Doñana, paraíso de las aves." Blanco y Negro, 2880, pp. 86-95 y "Fauna Ibérica 14. Una semana con los ornitólogos de Doñana." Blanco y Negro, 2881, pp. 84-93. También cabe señalar la portada del número 2864 de Blanco y Negro, del 25 de marzo de 1967, en la que se anuncia, precisamente, el comienzo de los reportajes de Félix Rodríguez de la Fuente sobre la fauna ibérica con una foto de un lince ibérico en Doñana; y el protagonismo del Coto en el reportaje que cierra esta primera serie, "Fauna Ibérica (y 15). Primera etapa de un viaje zoológico ibérico", publicado en el número 2882 el 22 de julio de 1967. Fuente: Hemeroteca ABC. 
5. Los dos programas exclusivos sobre Doñana fueron Planeta Agua. El Coto de Doñana I y Planeta Agua. El Coto de Doñana II, emitidos el 26 de octubre y el 2 de noviembre de 1975 en Radio Nacional de España (Archivo de la Fundación Félix Rodríguez de la Fuente; http://www.rtve.es/alacarta/audios/la-aventura-dela-vida/. [Radiotelevisión Española. 30 años sin Félix. La aventura de la vida. Fecha de consulta: 5 de agosto de 2015]).

6. En esta entrevista Doñana está en el centro de la argumentación sobre problemáticas medioambientales. Archivo FFRF, c. 12.

7. Los textos sobre Félix Rodríguez de la Fuente escritos por autores como Benigno Varillas, Joaquín Araújo, Miguel Delibes de Castro, Miguel Pou o Miriam Salcedo, citados en este artículo, son una muestra de la ingente producción laudatoria sobre su vida y obra. Todos ellos giran en torno a la idea de que hay un antes y un después de Rodríguez de la Fuente en la percepción de la naturaleza y las ciencias naturales en España. Incluso textos abiertamente críticos, como el libro de Fernando L. Rodríguez Jiménez, también citado aquí, insisten en este punto de vista (Tabernero, 2014a). Miguel Delibes de Castro también lo argumenta del mismo modo en la entrevista que cierra este monográfico (Tabernero y Varillas, Conservacionismo, ciencia y comunicación. Entrevista a Miguel Delibes de Castro).

8. En este sentido, es necesario tener en cuenta también su papel como celebridad, que se refleja en publicaciones y formatos en principio muy alejados de la comunicación científica, como los reportajes que se prodigaban sobre él y su familia en revistas del corazón.

9. Radiotelevisión Española. 30 años sin Félix. http://www.rtve. es/television/30-anos-sin-felix/. [Fecha de consulta: 5 de agosto de 2015].

10. Un ejemplo precisamente claro lo ofrece Miguel Delibes de Castro en la entrevista que cierra este monográfico mencionando las valoraciones de José Antonio Valverde, mentor de Rodríguez de la Fuente y uno de los principales impulsores de la protección de Doñana, sobre las diferencias en el impacto de lo que él, como biólogo, aportaba desde el ejercicio de las ciencias naturales, y lo que Félix Rodríguez de la Fuente decía en sus programas (véase en este mismo número Tabernero y Varillas, Conservacionismo, ciencia y comunicación. Entrevista a Miguel Delibes de Castro).

11. Véase también lo que Miguel Delibes de Castro comenta en la entrevista que cierra este monográfico acerca de las limitaciones del esfuerzo de Televisión Española para con los programas de Rodríguez de la Fuente (Tabernero y Varillas, Conservacionismo, ciencia y comunicación. Entrevista a Miguel Delibes de Castro).

12. Debido a su objeto de estudio, este artículo tiene necesariamente muchas referencias cruzadas con otras tres contribuciones a este monográfico, especialmente con el artículo sobre Félix Rodríguez de la Fuente (Tabernero, «La libertad de todos los seres vivos». Naturaleza, ciencias naturales y la imagen de España en la obra de Félix Rodríguez de la Fuente), pero también con el artículo sobre Doñana (Camprubí, La naturaleza no existe: conservacionismos y relaciones internacionales en Doñana) y con la entrevista a Miguel Delibes de Castro (Tabernero y Varillas, Conservacionismo, ciencia y comunicación. Entrevista a Miguel Delibes de Castro).

13. Cuatro capítulos, de un total de dieciocho, se dedicaron a los Yanomamos: Los Yanomamos, un pueblo de la selva, emitido el 17 de abril de 1974, En busca de los indios del Orinoco, emitido el 18 de mayo de 1974, El pueblo bravo, emitido el 8 de junio de 1974, y Un campamento en la selva virgen, emitido el 11 de junio de 1974 (MECD/INTEF, 2006a).

14. Como por ejemplo: los Campamentos de Verano en el Refugio de Rapaces de Montejo de la Vega, promovido por Rodríguez de la Fuente en 1974 (Varillas, 2010) Véase: WWF/España. Historia del Refugio de Rapaces de Montejo de la Vega [en línea] http:// www.wwf.es/que_hacemos/refugio_de_montejo/; WWF/España. WWF cumple 40 años protegiendo el Refugio de Rapaces de Montejo de la Vega (13 de enero de 2015) [en línea] http://www. wwf.es/?32660/WWF-cumple-40-aos-protegiendo--el-Refugiode-Rapaces-de-Montejo-de-la-Vega [Fecha de consulta: 5 de agosto de 2015]; su actividad desde Adena, fundamentalmente a través del Club de los Linces, establecido en 1968, o de iniciativas como “Reserva el Rincón. El mundo de Félix”, establecida en 1978.

15. Como en las revistas Gran Pulgarcito (1970) o Lince (1978).

16. Archivo FFRF.

17. Archivo FFRF, c. 41

18. Véase lo que ya se ha indicado en la nota 5 .

19. La conjunción de ciencia, educación y modernización formaba parte del ideario y las políticas en muy diferentes niveles de Manuel Fraga en su etapa al frente del Ministerio de Información y Turismo, donde la televisión pública y exclusiva jugaba un papel esencial.

20. Véase lo que se ha indicado en la nota 1.

21. Su primera aparición en televisión, en el programa Fin de Semana el 24 de noviembre de 1964, fue para hablar de cetrería al abrigo de su amigo y anteriormente jefe del Servicio Nacional de Caza y Pesca Fluvial, Jaime de Foxá (Varillas, 2010).

22. No en vano esta especie también merecería cuatro capítulos de la serie: El lobo, El cazador social, El clan familiar y Matadores inocentes, emitidos respectivamente, el 18 de febrero de 1977, y el 8 de marzo, el 31 de marzo y el 7 de abril de 1978. A estos cuatro capítulos se puede añadir El hombre y el lobo, uno de los capítulos póstumos coordinados por Joaquín Vera y Joaquín Araújo, y emitido el 2 de mayo de 1981 (MECD/INTEF, 2006b).

23. Sus llamadas en medios de amplia difusión a cambios en las políticas relacionadas con la gestión del patrimonio natural comienzan con la publicación en marzo de 1960 de un artículo en el diario $A B C$ ( 2 de marzo en la edición de Madrid, y 3 de marzo en la edición de Sevilla), "Las aves nobles no deben ser tratadas como alimañas", en defensa de las aves de presa frente a las Juntas Provinciales de Extinción de Animales Dañinos (véase en este mismo número Tabernero «La libertad de todos los seres vivos». Naturaleza, ciencias naturales y la imagen de España en la obra de Félix Rodríguez de la Fuente).

24. Emitido el 10 de febrero de 1978 (MECD/INTEF, 2006b).

25. Decreto 2412/1969. Boletín Oficial del Estado 257, 27 de octubre de 1969, pp. 16789-16790.

26. Ley 91/1978. Boletín Oficial del Estado 11, 12 de enero de 1979, pp. 813-815.

27. José Antonio Valverde fue un actor esencial en el establecimiento de la Estación Biológica de Doñana en 1965 y del Parque Nacional en 1969. Además, también fue, indudablemente, uno de los personajes fundamentales en el desarrollo profesio- 
nal de Félix Rodríguez de la Fuente como naturalista y activista conservacionista, a partir del apoyo que le ofreció, cuando se encontraron en Valladolid en 1952, en relación con su interés por la cetrería (Valverde, 2004; Varillas, 2010; véase también en este mismo número Camprubí, La naturaleza no existe: conservacionismos y relaciones internacionales en Doñana).

28. Archivo FFRF, c. 22.

29. El Parque Nacional de Doñana IV. La ronca de los gamos.

30. El Parque Nacional de Doñana IV. La ronca de los gamos. Énfasis añadido.

31. El Parque Nacional de Doñana IV. Viajeros africanos.

32. Algunas de estas expresiones utilizadas, en orden de aparición, a lo largo de los cuatro capítulos: "[n]osotros aprovechamos estos momentos de transición para mostrarles [...]" (El Parque Nacional de Doñana I. La invernada de los gansos); "[...] tenemos nosotros la oportunidad de descubrir [...]", "[y] podemos nosotros contemplar [...] por eso tienen mayor interés estas filmaciones [...]", "[n]o nos hemos atrevido a turbar antes su delicada infancia con la presencia de nuestras cámaras.", "[c] omo pudimos comprobar a lo largo de nuestras filmaciones [...]", "[h]emos tenido la oportunidad de contemplar [...]" (EI Parque Nacional de Doñana II. El paraíso de las garzas); "[e]I plano de la familia de gamos traspasado de luz viene a llamar la atención de nuestros operadores.", "[h]a llegado el momento de que descubramos [...]", "[...] alertados quizás por el motor de nuestras cámaras [...]", "[t]engamos la paciencia que ostentan los operadores de nuestra serie, y muy pronto descubriremos las intenciones de los milanos negros.", "[s]orprendemos ahora al macho que aporta una gran ave blanca [...]" (El Parque Nacional de Doñana III. Viajeros africanos); "[y] nosotros, ami-

\section{BIBLIOGRAFÍA}

Alcalá-Lorente, M. y Tabernero, C. (2014). The wise vulture, or discourses of modernization in wildlife television documentaries in 1970s Spain. 6th International Conference of the European Society for the History of Science. Lisboa (Portugal), septiembre 2014.

Aldridge, M. y Dingwall, R. (2003). Teleology on Television? Implicit Models of Evolution in Broadcast Wildlife and Nature Programmes. European Journal of Communication, 18 (4), pp. 435-453. http://dx.doi.org/10.1177/0267323103184001

Araújo, J. (1990). La Voz de la Naturaleza: biografía de Félix Rodríguez de la Fuente. Barcelona: Salvat.

Boon, T. (2008). Films of Fact: A History of Science in Documentary Film and Television. Londres/Nueva York: Wallflower Press.

Boon, T. (2014). Formal conventions in British science television (1955-1965). Actes d'Història de la Ciència i de la Tècnica, 7, pp. 51-69.

Bousé, D. (2000). Wildlife films. Philadelphia: University of Pennsylvania Press. http://dx.doi.org/10.9783/9780812205848

Brockington, D. (2008). Powerful environmentalisms: conservation, celebrity and capitalism. Media, Culture \& Society, 30 (4), pp. 551-568. http://dx.doi.org/10.1177/01634437080300040701 gos, estábamos allí para contarles con puntualidad todo el devenir de las especies que constituyen la magnífica comunidad de nuestro Parque Nacional.", "[y] hemos filmado precisamente esta familia para demostrar [...]", "[c]omprobamos nosotros $[\ldots]$ ", "[...] como hemos comprobado [...]", "[e]l gamo [...] nos brinda esta prodigiosa exhibición que trata de llamar la atención de sus congéneres que hay algo insólito y perturbador: precisamente, amigos, la presencia de nuestra cámara." (El Parque Nacional de Doñana IV. La ronca de los gamos).

33. Un ejemplo en el que se utiliza este tipo de expresiones relacionades con la importancia del Parque en el ámbito internacional: "la importancia de la marisma de Doñana como creadora y mantenedora de una gran biomasa ornítica se encuentra a la cabeza de cualquier otro parque o santuario de Europa." El Parque Nacional de Doñana I. La invernada de los gansos. Énfasis añadido.

34. BBC. History of the BBC. John Reith. 5. This is the BBC 1922-1926 [en línea] http://www.bbc.co.uk/historyofthebbc/research/ culture/reith-5. [Fecha de consulta: 5 de agosto de 2015].

35. Radiotelevisión Española. Informe Semanal. http://www.rtve. es/noticias/informe-semanal. [Fecha de consulta: 5 de agosto de 2015].

36. Internet Movie Data Base / Proyecto UFO: Investigación OVNI (H. J. Bloom, 1978) http://www.imdb.com/title/tt0077065/ combined. [Fecha de consulta: 5 de agosto de 2015].

37. Radiotelevisión Española. La segunda oportunidad. http:// www.rtve.es/alacarta/videos/para-todos-la-2/para-todos2-para-todos-tele-segunda-oportunidad/2859418. [Fecha de consulta: 5 de agosto de 2015].

Cabeza San Deogracias, J. y Mateos-Pérez, J. (2013). Thinking about television audiences: entertainment and reconstruction in nature documentaries. European Journal of Communication, 28 (5), pp. 570-583. http://dx.doi. org/10.1177/0267323113494075

Chris, C. (2006). Watching wildlife. Minneapolis: University of Minnesota Press.

Collins, H. (1987). Certainty and the public understanding of science: science on television. Social Studies of Science, 17 (4), pp. 689-713. http://dx.doi.org/10.1177/030631287017004005

Davies, G. (2000). Science, observation and entertainment: competing visions of postwar British natural history television, 19461967. Cultural Geographies, 7 (4), pp. 432-460. http://dx.doi. org/10.1177/096746080000700403

Díaz, L. (2006). 50 años de TVE. Madrid: Alianza.

Dingwall, R. y Aldridge, M. (2006). Television wildlife programming as a source of popular scientific information: a case study of evolution. Public Understanding of Science, 15 (2), pp. 131-152. http://dx.doi.org/10.1177/0963662506060588

Dugan, D. (2014). The secret of science storytelling in TV documentaries. Actes d'Història de la Ciència i de la Tècnica, 7, pp. 35-49. 
Duque, A. (1977/2004). El mito de Doñana. Sevilla: Fundación José Manuel Lara.

Florensa, C., Hochadel, O. y Tabernero, C. (2014a). Science on television: Theory meets practice. An introduction. Actes d'Història de la Ciència i de la Tècnica, 7, pp. 11-16.

Florensa, C., Hochadel, O. y Tabernero, C. (2014b). Science on television: Audiencies, markets and authority. Some conclusions. Actes d'Història de la Ciència i de la Tècnica, 7, pp. 127-136.

Galison, P. (2014). Visual STS. En: Carusi, A., Hoel, A. S., Webmoor, T. y Woolgar, S. (eds.) Visualization in the age of computerization. Nueva York: Routledge, pp. 197-225.

Gouyon, J.B. (2011). The BBC Natural History Unit: Instituting Natural History Film-making in Britain. History of Science, XLIX, pp. 425-451.

Guzmán, M. y Tabernero, C. (2016). The city in waves: Radio BarceIona and urban everyday life. En: Hochadel, O. y Nieto-Galán, A. (eds.) Barcelona (1888-1929). An urban history of science and modernity. Oxford: Routledge, pp. 200-222.

Horak, J. C. (2006). Wildlife documentaries: from classical forms to reality TV. Film History, 18 (4), pp. 459-475. http://dx.doi. org/10.1353/fih.2007.0000

Jenkins, H. (2006). Fans, Bloggers, and Gamers: Exploring Participatory Culture. New York: New York University Press.

Jenkins, H. (2010). Transmedia Storytelling and Entertainment: An Annotated Syllabus. Continuum: Journal of Media \& Cultural Studies, 24 (6), pp. 943-958. http://dx.doi.org/10.1080/10304 312.2010.510599

Jones, A. (2011). Mary Adams and the producer's role in early BBC science broadcasts. Public Understanding of Science, 21 (8), pp. 968-983. http://dx.doi.org/10.1177/0963662511419450

LaFollette, M. C. (2002). A Survey of Science Content in U.S. Radio Broadcasting, 1920s through 1940s: Scientists Speak in Their Own Voices. Science Communication, 24 (1), pp. 4-33. http:// dx.doi.org/10.1177/107554700202400102

LaFollette, M. C. (2012) Science on American Television. A History. Chicago: University of Chicago Press. http://dx.doi.org/10.7208/ chicago/9780226922010.001.0001

Lehmkuhl, M. (2014). Current state and challenges of science in today's TV: a look on the interplay between supply and demand on European media markets. Actes d'Història de la Ciència i de la Tècnica, 7, pp. 89-112.

León, B. (1999). El documental de divulgación científica. Barcelona: Paidós.

León, B. (coord.) (2010). Ciencia para la television. El documental científico y sus claves. Barcelona: UOC

Mitman, G. (1999). Reel nature: America's romance with wildlife on films. Cambridge: Harvard University Press.

Moreno Díaz, J. (2014). Los concursos en España: percepción histórica y evolución del género (1956-1975). Estudios sobre el Mensaje Periodístico, 20 (núm. especial), pp. 27-42. http://dx.doi. org/10.5209/rev_ESMP.2014.v20.45089

Ojeda Rivera, J. F., González Faraco, C. y López Ontiveros, A. (eds.) (2006). Doñana en la cultura contemporánea. Madrid: Ministerio de Medioambiente.
Ortega Gálvez, M. L. y Albertos, A. (1998). La ciencia en Televisión Española: primeros acercamientos a la divulgación. Secuencias, 8, pp. 61-74.

Palacio, M. (2001). Historia de la televisión en España. Barcelona: Gedisa.

Pou, M. (1995). Félix Rodríguez de la Fuente. El hombre y su obra. Barcelona: Planeta.

Ramos Cumplido, J. M. (2001). Qué lugar más hermoso para morir. Crónicas inéditas sobre la vida y muerte de Félix Rodríguez de la Fuente. Madrid: Raíces.

Rodríguez Jiménez, F. L. (2006). Así se hizo: 1. El Hombre y la Tierra. Madrid: Naturaventur.

Rueda Laffond, J. C. (2005). La televisión en España: expansión y consumo social, 1963-1969. Anàlisi, 32, pp. 45-71.

Rueda Laffond, J. C. y Coronado Ruiz, C. (2010). La codificación televisiva del franquismo: de la historia del entretenimiento a la historia como entretenimiento. Historia Crítica , 40, pp. 170-195. http://dx.doi.org/10.7440/histcrit40.2010.10

Salcedo de Prado, M. (2008). El documental de divulgación científica sobre la naturaleza: técnicas narrativo-dramáticas y retóricas empleadas por Félix Rodríguez de la Fuente en 'El Hombre y la Tierra'. Pamplona: Universidad de Navarra.

Scott, K. D. (2003). Popularizing Science and Nature Programming: The Role of "Spectacle" in Contemporary Wildlife Documentary. Journal of Popular Film and Television, 31 (1), pp. 29-35. http:// dx.doi.org/10.1080/01956050309602866

Silverstone, R. (1994). Television and everyday life. Londres: Routledge. http://dx.doi.org/10.4324/9780203358948

Tabernero, C. (2016). Cine y procesos de medicalización: documentales médico-coloniales de la posguerra española (1946-1949). En: Brigidi S. (ed.) Cultura, Salud, Cine y Televisión. Tarragona, Publicacions de la Universitat Rovira i Virgili, pp. 169-207.

Tabernero, C., Jiménez Lucena, I., Molero, J. (2012). Scientific-medical knowledge management through media communication practices: a review of two opposite models in early $20^{\text {th }}$ century Spain. Journal of History of Science and Technology 6 (Fall), pp. 64-84.

Thompson, J. B. (1995). The Media and Modernity. A Social Theory of Media. Cambridge: Polity Press.

Úbeda, J. (2014). Creative strategies for scientific TV documentaries. Actes d'Història de la Ciència i de la Tècnica, 7, pp. 71-88.

Valverde, J. A. (2004). Memorias de un biólogo heterodoxo (tomo IV. La aventura de Doñana. Cómo crear una reserva). Madrid: $\mathrm{V} \& \mathrm{~V} /$ Quercus.

Varillas, B. (2005). El ecologismo español desde Félix hasta nuestros días. En: VV.AA. Félix, 25 años de conciencia ecológica. Madrid: Fundación BBVA / Fundación Félix Rodríguez de la Fuente, pp. 121-129.

Varillas, B. (2010). Félix Rodríguez de la Fuente. Su vida, mensaje de futuro. Madrid: Fundación Félix Rodríguez de la Fuente/La Esfera de los Libros.

VV.AA. (2006). Félix, 25 años de conciencia ecológica. Madrid: Fundación BBVA / Fundación Félix Rodríguez de la Fuente.

Wheatley, H. (2004). The limits of television? Natural history programming and the transformation of public service 
broadcasting. European Journal of Cultural Studies, 7 (3), pp. 325-339. http://dx.doi.org/10.1177/1367549404044786

Wheatley, H. (2013). At Home on Safari: Colonial Spectacle, Domestic Space and 1950s Television. Journal of British Cinema and Television, 10 (2), pp. 257-275. http://dx.doi.org/10.3366/ jbctv.2013.0134

\section{Recursos de Internet}

Ministerio de Educación, Cultura y Deporte / Instituto Nacional de Tecnologías Educativas y de Formación del Profesorado (2006a).50 años de televisión en España. Prado del Rey: el UHF y la expansión. Programación. [En línea]. [Fecha de consulta: 2 de enero de 2015] Disponible en: http://tv_mav.cnice.mec.es/siglo/50/.
Ministerio de Educación, Cultura y Deporte / Instituto Nacional de Tecnologías Educativas y de Formación del Profesorado (2006b). 50 años de televisión en España. La transición política. Programación. [En línea]. [Fecha de consulta: 2 de enero de 2015] Disponible en: http://tv_mav.cnice.mec.es/siglo/50/. 